\title{
An assessment of heterogeneity in first home-returning trends of young Canadians
}

\author{
Jean-Michel Billette \\ Microdata Access Division, Statistics Canada \\ jean-michel.billette@statcan.gc.ca \\ Céline Le Bourdais \\ Department of Sociology, McGill University
}

\author{
Benoît Laplante \\ Institut National de la Recherche Scientifique \\ Centre Urbanisation, Culture et Société (Montréal)
}

\begin{abstract}
This study uses data taken from the 2001 General Social Survey on family bistory (GSS, Cycle 15) to examine bome-returning among Canadian men and women born in 1942-76. In addition to conducting a detailed analysis of the numerous factors at play in determining the likelihood of home-returning, we pay specific attention to the timing of the transition and provide an estimation of the overall influence of unobserved characteristics that contribute to generate home-returners. Results suggest that early, intermediate, and late home-returners have different socio-demographic profiles and that unobserved characteristics play a significant part in the determination of home-returning.
\end{abstract}

Keywords: home-returning, life course, piecewise exponential model, unobserved heterogeneity.

\section{Résumé}

Cette étude utilise des données tirées de l'Enquête rétrospective sur la famille de 2001 (cycle 15 de l'Enquête sociale générale) afin d'examiner le retour vers le milieu familial au Canada au sein des cohortes 1942-1976. En plus d'effectuer une analyse détaillée des facteurs jouant un rôle dans le processus de rupture de l'autonomie résidentielle, nous accordons une importance particulière au calendrier de l'événement ainsi qu'à l'influence de caractéristiques individuelles inobservées. Nos résultats suggèrent que le profil sociodémographique des jeunes varie en fonction du calendrier des retours (précoces, intermédiaires ou tardifs) et que des caractéristiques inobservées jouent un rôle significatif dans la détermination de l'événement.

Mots-clés : retour vers le milieu familial, parcours de vie, modèle exponentiel par parties, hétérogénéité non observée. 


\section{Introduction}

A substantive body of literature has been written on the very topic of home-leaving and its relationship to recent sociological changes in the timing and experience of the entry into adulthood. These studies usually converge in showing that, in many Western countries, the co-residency rates of adult children with their parents are skyrocketing due to two main factors: a strong trend to delay home-leaving and an unprecedented propensity among young adults to flock back to the nest once they have left. Although the former phenomenon has received increased attention over the past 20 years or so, the latter has remained relatively understudied, mainly because reliable national-level data were either scarce or unavailable until recently.

Within the context of a cross-national comparison drawing on several data sources from Britain, Canada, France, Germany, Sweden, and the United States, Mitchell (2006a) reports that in 2001, 28 per cent of young Canadian women and 33 per cent of young Canadian men had experienced at least one return home after an initial departure. Of all the countries taken into consideration for the purpose of this cross-national comparison, Canada is outranked by only one "competitor," namely, the United States, where the overall estimate of home-returning for both sexes reaches 40 per cent (original source: Goldscheider et al. 1999).

Other recent Canadian studies based on retrospective data drawn from the 2001 General Social Survey on the family have reported similar home-returning estimates. For instance, Beaupré et al. (2006) found that the probability of returning home within five years of a first departure has increased from 12 to 32 per cent for men, and from 10 to 28 per cent for women between early baby boomers (generations 1947-51) and late Gen-Xers (generations 1972-6). Another study by Billette et al. (2006) estimated that the proportions of men and women born between 1972 and 1976 who had returned home by their thirtieth birthday were 32.4 and 30.4 per cent, respectively. Furthermore, their results also suggest that the trend towards a substantial increase from one cohort to another is likely to affect younger generations as well, probably at a faster pace than what had been observed hitherto.

Explanations have been put forward as to why such a rapid and notable change in home-returning behaviours has occurred. Most researchers agree that the demise of marriage as the foremost destination out of the family nest stands as a primary explanatory factor (Goldscheider and Goldscheider 1993, 1999; Gee et al. 1995; Goldscheider et al. 1999; Mitchell et al. 2000; Corijn and Klijzing 2001; Beaupré et al. 2006; Mitchell $2006 \mathrm{a}, 2006 \mathrm{~b})$. It is also acknowledged that macro-level economic factors, along with the extended upsurge in both the rate and duration of post-secondary education enrolment, have played a considerable part in making home-returning a popular reverse transition (Goldscheider et al. 1999; Paul 2001). Other studies have also stressed the relevance of intergenerational relations in the decision-making process of leaving/returning home (Bozon and Villeneuve-Gokalp 1994; Mitchell and Gee 1996; Mitchell et al. 2002).

Nevertheless, recent estimates of cohort-specific patterns of home-returning in Canada have shown that, when asked to report the main reason underlying their decision to return to the parental home, 16.7 per cent of male respondents and as many as 33.5 per cent of female respondents born between 1962 and 1981 mention that they did so for a reason that has nothing whatsoever to do with school-related factors, employment, union disruption, or financial insecurity. Especially striking in the case of women, these 
results differ in essence from home-leaving estimates, according to which a vast majority of respondents either left for school, work, marriage/cohabitation, or to achieve independence, hence leaving little room for a residual category of home-leavers (Billette et al. 2006).

Building on these findings, this paper intends to further investigate the impact of unobserved differences between individuals with respect to nest-refilling behaviours. Although we recognise that some standard demographic and socio-economic determinants have a non-negligible impact on the occurrence of this reverse transition, our goal here is to measure the extent to which the additional unobserved characteristics of different cohorts of young Canadians might as well contribute to fuel this phenomenon. If our hypothesis that a significant part of the home-returning process, at the Canadian level, can be accounted for by unobserved differences appears to be empirically verified, this would eventually highlight the need for further qualitative research in the broad field of the transition to adulthood, as well as the necessity to reconsider the content of the survey questionnaires that deal with such issues.

\section{Theoretical considerations}

This article relies heavily on many essential tenets of the life course paradigm (Elder 1985, 1995, 2003; Hagestad and Neugarten 1985). Central to our hypothesis is the idea that experiential heterogeneity acts as a key concept to capturing the ins and outs of the residential facet of the transition to adulthood. Heterogeneity in the timing and sequencing of individual and family-related transitions is emphasized as one of the main focuses of the life course perspective, which therefore stands in plain contrast with the more rigid life cycle approach that depicts these transitions as being linear and almost universal. Consequently, the life course perspective acknowledges diversity and variability in processes, whereas the life cycle approach gives prominence to average trends and normative sequences. Since home-returning is usually conceptualized as a reverse transition conditional on home-leaving, which is in turn envisioned as a "standard" life course transition, one could hardly quibble that it is duly part of a generalized linear sequence.

It is nowadays commonplace to state that in industrialized societies, the past few generations of young adults who experienced the transition to adulthood between the early 1980s and today tended to do so in a more individualistic manner than previous cohorts, whose members had conformed for the most part to a well-defined clear-cut sequence of events. It is therefore crucial to make room for individual differences when tackling the study of a life event such as home-returning. Yet it is also important to recognise that most of the individual differences that can be observed with regard to this transition reversal are to be construed as systematic and do not simply emerge from a mere collection of events or decisions totally contingent upon each individual's life history. Individuals are nested in a variety of higher-level categories that shape their behaviours and attitudes, and make them more or less likely to act in a certain way at a given moment of their lives. Gender, cohort membership, marital status, family background, ethnocultural environment, educational attainment, and employment status are all systematic characteristics that influence the choices an individual will eventually make with respect to a particular context or a given set of diverse opportunities. This does not imply that all the individuals who share a common characteristic are condemned to monolithically experience the same circumstances, at the same time, in a dramatically deterministic manner. The life 
course perspective makes allowance for variation within social categories as well as between them. From a probabilistic standpoint, however, some characteristics make people more or less prone to make certain decisions, while some others do not.

Such characteristics as those listed above will be included in our explanatory model of home-returning trends (see next section). By controlling for cohort membership, we therefore acknowledge that generational time ${ }^{1}$ is likely to play a major role in the determination of individual trajectories, and that the sequences of transitions that were an integrated part of many baby boomers' young adulthood are assumed to be of a different nature than those shaping the lives of young adults today. Furthermore, by taking into consideration characteristics that relate to the timing of individual transitions, such as exiting from school or entering the labour force, we also recognise that individual time is of great relevance when it comes to explaining one particular transition (or transition reversal), and that specific events and decisions are highly contingent upon previous life course experiences.

However, we hypothesise that available survey data do not suffice to capture the diversity of scenarios that may be involved in the determination of home-returning. Consistent with this hypothesis are the high proportions of individuals reporting that their main reason for returning home was not at all related to employment, education, conjugal disruption, or economic precariousness (Mitchell 2004; Billette et al. 2006). Many factors may eventually contribute to the reversal of residential independence, and not all of them are systematic. For instance, some young adults may come back home because they have just graduated from college, while some others return after a long backpacking journey across the world. The first of these transitions is systematic and conforms to a wellestablished pattern that is easy to identify with a standard survey questionnaire, whereas the second one refers to a life course experience that is rather difficult to grasp without a detailed interview of the individual. We believe that a significant proportion of young adults who experienced at least one episode of home-returning did so in a more or less non-systematic manner (e.g., because their apartment burned down, or they were unable to cope with their roommates, or they were poor at preparing edible meals, or they were suffering from depression and needed assistance), and the present article aims to verify this hypothesis with respect to the life course trajectories of men and women.

\section{Data, variables and methods}

\section{Sample}

Our data come from the 2001 General Social Survey (GSS, Cycle 15) on family history, conducted from February through December 2001 by Statistics Canada and representative of all Canadians aged 15 and older who were not residing in the Yukon, Northwest Territories, or Nunavut, and who were not full-time residents of an institution at the time they were interviewed. Respondents were contacted through means of Random Digit Dialling (RDD), a telephone sampling method. ${ }^{2}$ Retrospective information relating to the respondents' family, school, work, and migratory trajectories was collected,

1. For a detailed definition of individual time, generational time, and historical time, see Price et al. (2000).

2. The RDD method employed for the survey is known as the Elimination of Non-Working Banks (ENWB) sampling technique. This technique attempts to eliminate from the sampling frame all the banks that are not residential, i.e., that do not contain at least one telephone 
as well as other information about their fertility intentions, and their values and attitudes towards such topics as money, marriage, and family relations. For the purpose of the survey, each province was divided into strata and separate samples were selected within each stratum. As a consequence of this multi-stage survey design, respondents have unequal probabilities of selection; sampling weights were computed in order to account for both non-randomness and non-response. All the estimates presented in this paper are thereby weighted accordingly.

Overall, the sample is composed of 24,310 respondents (10,664 men and 13,646 women). For the sake of our analysis, only people born between 1942 and 1976 were selected (see below), thus resulting in the loss of 3,625 men and 5,145 women. Moreover, age at first return was missing for 736 men and 618 women, and information concerning one or many independent variables was also missing for 1,500 male respondents and 2,211 female respondents. ${ }^{3}$ As a result, our final analytic sample consists of 4,803 men and 5,672 women, among whom 1,064 (22.1 per cent) men and 1,181 (20.8 per cent) women had experienced a first return home within 10 years of an initial departure.

\section{Dependent variable}

The dependent variable in our analytic model is the instantaneous hazard of experiencing a first return to the parental home within the ten years following a first departure. People are considered at risk of returning home from the very moment they leave the family nest for the first time. ${ }^{4}$ In order to account for heterogeneity in the timing of this reverse transition, period-specific estimates are computed for three different time pieces: the first year (early returns), the second and third years (intermediate returns), and the remaining seven years (late returns). Slightly more than two-fifths of the returners fall into the first category ( $\mathrm{M}=46.4$ per cent, $\mathrm{F}=43.5$ per cent), while less than one-third are intermediate returners $(\mathrm{M}=29.8$ per cent, $\mathrm{F}=31.5$ per cent $)$, and less than one-fourth came back after at least three full years $(\mathrm{M}=23.8$ per cent, $\mathrm{F}=24.6$ per cent). These cut points are impossible to justify from a theoretical standpoint, since no previous study on the topic has estimated multiple-hazard ratios for one single-hazard function. They were simply selected over a set of alternate options based on goodness-of-fit comparisons.

Higher-order returns are not taken into consideration in this study, for detailed information was only available with regard to the first and last returns, the latter category encompassing returns of various orders. Furthermore, information concerning the last return was solely gathered among respondents who were co-residing with their parents at the time of the survey. Hence, an attempt at studying multiple-return episodes would have ultimately resulted in a selection bias problem, given the small number of age-homogeneous respondents for whom dated information on the last return home was available.

number attributed to a private household. A bank is defined as a set of 100 telephone numbers with the same first eight digits.

3. Included in the total count of missing values are the individuals whose first return home was not accomplished on the Canadian territory. These numbers also take into consideration the fact that people who had never left the parental home at the time of the survey were excluded from our risk set.

4. The following questions are used to assess the timing of home leaving and returning: "In what month and year did you first/last leave home to live on your own?" and "In what month and year did you start living with your parent(s) again for the first/last time?" Consequently, there is no specification of a minimal duration away from/back to the parental home that would serve as a baseline criterion to define a departure/return. 
Table 1. Per cent distribution of independent variables by gender.

\section{1-Generational factor}

Men Women

Birth cohort

\section{2-Family background characteristics}

$\begin{array}{rrr}1942-46 & 9.5 & 10.1 \\ 1947-51 & 13.8 & 13.2 \\ 1952-56 & 15.8 & 16.0 \\ 1957-61 \text { (ref.) } & 17.1 & 17.0 \\ 1962-66 & 17.3 & 17.3 \\ 1967-71 & 14.6 & 14.2 \\ 1972-76 & 11.9 & 12.1\end{array}$

Family structure prior to age 15

$\begin{array}{rrr}\text { Biparental intact family (ref.) } & 87.4 & 85.8 \\ \text { Adoptive family } & 0.9 & 1.3 \\ \text { Stable lone-parent family } & 5.8 & 6.7 \\ \text { Stable step-family } & 1.2 & 1.5 \\ \text { Alternation step-family + lone-parent family } & 1.9 & 2.3 \\ \text { Other } & 2.9 & 2.3\end{array}$

Presence of half/step-siblings

$\begin{array}{rrr}\text { Yes } & 11.0 & 13.0 \\ \text { No (ref.) } & 89.0 & 87.0\end{array}$

Total number of siblings

$$
\text { Mean (s.d.) }
$$

Highest level of education of most educated parent

Less than secondary (ref.)

Mother worked prior to age 15

Religious attendance at age 15

$$
\begin{array}{r}
\text { Yes } \\
\text { No (ref.) }
\end{array}
$$

Size of the city where respondent lived at age 15

Emotional closeness to mother when a child

$90.0 \quad 85.0$

$10.0 \quad 15.0$

Emotional closeness to father when a child

$$
\begin{array}{r}
\text { Close (ref.) } \\
\text { Not close }
\end{array}
$$

Had a happy childhood

$$
\text { Close (ref.) }
$$

29.6

28.5

$$
\text { Yes (ref.) }
$$




\begin{tabular}{|c|c|c|}
\hline (Table 1, cont'd.) & Men & Women \\
\hline No & 9.5 & 14.0 \\
\hline $\begin{array}{l}\text { 3-Demographic + socio-economic factors } \\
\text { Work status }{ }^{a}\end{array}$ & & \\
\hline Does not work (ref) & 15.1 & 29.3 \\
\hline Works part-time & 1.9 & 14.2 \\
\hline Works full-time & 83.0 & 56.5 \\
\hline Marital status ${ }^{a}$ & & \\
\hline No union (ref.) & 44.2 & 39.6 \\
\hline Common-law union & 1.8 & 2.1 \\
\hline Marriage & 54.0 & 58.3 \\
\hline Level of education ${ }^{a}$ & & \\
\hline Less than secondary (ref.) & 18.7 & 16.4 \\
\hline High school & 33.3 & 36.4 \\
\hline Postsecondary & 23.2 & 24.8 \\
\hline University & 24.8 & 22.4 \\
\hline School completion ${ }^{\mathrm{a}}$ & & \\
\hline Yes & 77.4 & 77.7 \\
\hline No (ref.) & 22.6 & 22.3 \\
\hline Region of birth of mother & & \\
\hline Canada (ref) & 73.3 & 72.5 \\
\hline Rest of the American continent & 3.4 & 4.0 \\
\hline Europe & 15.6 & 15.7 \\
\hline Asia & 6.0 & 6.0 \\
\hline Africa/Oceania & 1.7 & 1.9 \\
\hline Mother tongue & & \\
\hline English (ref.) & 58.6 & 59.8 \\
\hline French & 26.3 & 25.1 \\
\hline Other & 15.1 & 15.1 \\
\hline Province of residence ${ }^{a}$ & & \\
\hline Quebec & 26.3 & 25.4 \\
\hline Rest of Canada & 73.7 & 74.6 \\
\hline $\begin{array}{l}\text { 4-Home-leaving characteristics } \\
\text { Age when first left home }\end{array}$ & & \\
\hline Less than 20 & 45.1 & 53.1 \\
\hline 20-24 (ref.) & 40.1 & 36.9 \\
\hline 25 and over & 14.8 & 10.0 \\
\hline Reason first left home & & \\
\hline Union & 24.7 & 39.1 \\
\hline School & 22.6 & 22.8 \\
\hline Work & 19.8 & 12.5 \\
\hline Independence (ref.) & 26.1 & 20.8 \\
\hline Other & 6.8 & 4.8 \\
\hline $\mathrm{N}$ & 4,803 & 5,672 \\
\hline
\end{tabular}

Totals that are not exactly equal to $100.0 \%$ are due to rounding. All frequencies are weighted using sampling weights supplied by Statistics Canada.

a: These variables are subject to vary over time. Percentages shown here are those at the moment respondents either experienced a first return home or exited the risk set.

Source: General Social Survey, Cycle 15. 


\section{Independent variables}

Four different types of factors are incorporated into our explanatory model: generational factors, family background factors, demographic and socio-economic factors, and factors related to the home-leaving context. Table 1 gives an overview of the relative frequencies for each category of every independent variable.

Generational factors. The first category of factors is represented by only one variable: cohort membership. As shown in the recent literature on the topic, there is an undeniable cohort effect that affects both the tempo and quantum of home-returning in Canada, with a risk that seems to be leapfrogging from one generation to another (Beaupré et al. 2006; Billette et al. 2006). Gen-Yers have a higher probability of experiencing a return home than Gen-Xers, who were, in turn, more likely to refill the nest than Boomers had been before them. In order to account for generational changes in the transition to adulthood, we here rely on 5-year birth cohorts, spanning from 1942 to 1976, thus focusing on people who were aged 25-59 when interviewed. In so doing, we can afford comparing people born during World War II (1942-6), baby boomers (1947-66), and Gen-Xers (1967-76). Unfortunately, since Gen-Yers (1977-86) were only aged 15-24 in 2001, and tend to leave and return at later ages than members of older cohorts, we made the decision not to include them in our risk set, for they would have been underrepresented as a consequence of the high proportion of individuals who had not been exposed long enough to the risk of returning home at the time of the survey, ${ }^{5}$ let alone those who had not even left home. As for respondents aged 60 and over, we excluded them from the final sample due to the potential inaccuracy of their responses regarding events that took place thirty to forty years before the interview. Birth years 1957-61 were chosen as the reference category, because they enclose members of the central cohort; also, there were about as many respondents who were born either before or after those dates in the analytical sample.

Family background factors. The second category of factors encompasses a wide array of variables that are somehow related to the respondents' youth and family background. We tried to capture the effect of family structure prior to age 15 by generating two variables: one that would account for the separate impacts of adoptive, lone-parent, step-parent families, and other family types (grandparent families, foster homes, cases of tutorship...), as opposed to stable two-parent families. In so doing, we realized that a non-negligible proportion of individuals ( $\sim 2$ per cent of the overall sample) had undergone at least one step-family and one lone-parent family episode by age 15 . Accordingly, a sixth category was created.

A continuous variable also controls for the total number of siblings (full, adopted, half, and step). Prior research has pointed out that family change and step/lone-parenthood usually decrease the odds of returning home (Aquilino 1990; White 1994; Gee et al. 1995; Tang 1997; Goldscheider and Goldscheider 1998; Mitchell et al. 2000; Beaupré et al. 2006), and so does the total number of siblings (Ward et al. 1992; Mitchell et al. 2000). We therefore expect our results to converge with those previously found.

Socio-economic status of the family of origin is modelled using two variables: the highest level of education ever attained by either the father or the mother of the re-

5 . We estimated that 75.6 per cent of young men and 66.3 per cent of young women born 1977-86 who had left home once had not returned by the time the survey was conducted, though their probability of experiencing at least one episode of home-returning should be close to 40 per cent (Beaupré et al. 2006; Billette et al. 2006). 
spondent, and the work status of the mother. Paternal work status was not taken into consideration here, because more than 90 per cent of the selected respondents reported that their father had worked full-time throughout their childhood, thus leaving little room for variance within our sample. Relying on previous findings on home-returning at the Canadian level, we hypothesize here that maternal work and overall parental education should have a positive impact on the risk of returning home (Wister et al. 1997; Mitchell et al. 2000; Beaupré et al. 2006).

Other covariates pertaining to the childhood of the respondents are also included in the model. Religious attendance and size of the city (both considered at age 15) should have a significant impact on the decision to return home. According to Beaupré et al. (2006), mildly religious individuals are more at risk of returning to the parental nest than those who attend religious services weekly. Findings from the same study also suggest that people who grew up in rural areas are less likely to return home than those who spent their childhood in larger cities. We also control for the retrospective perception of closeness to parents and childhood happiness. Although Mitchell et al. (2000) did not find any significant relationship between these factors and the propensity to return home, it might be hypothesized that people who are emotionally closer to their parents and feel they had a happy childhood will exhibit a greater proclivity to come back home than those with weaker family bonds and recollections of unhappiness. ${ }^{6}$

Demographic and socio-economic factors. The third group of factors refers to the demographic and socio-economic determinants that may have a certain influence on the decision of returning home. Employment status, marital status, level of education, and school enrolment are all modelled as time-varying covariates, whose values are subject to change as time goes on. Consequently, the frequencies appearing in Table 1 are those at the time respondents either returned home (for those who did), or were censored (for those who did not), i.e., at the last moment they contribute to the hazard function. Although no prior study has separately considered full-time and part-time work, ${ }^{7}$ it has been found that being employed reduces the risk of returning to the parental home (Gee et al. 1995; Beaupré et al. 2006). We therefore expect full-time work to have a negative impact on the dependent variable. The case of part-time work is less clear, and can be considered as a proxy for economic precariousness. ${ }^{8}$ From this standpoint, its impact should not significantly differ from that of unemployment.

Single individuals should face a higher risk of returning home than married ones (Gee et al. 1995; Goldscheider and Goldscheider 1999; Goldscheider et al. 1999). Com-

6. These variables were collected using an ordinal scale. Respondents were asked whether they strongly agreed, agreed, disagreed, or strongly disagreed with statements such as: "I had a very happy childhood;" "I was very close emotionally to my father/father substitutes when I was growing up;" "I was very close emotionally to my mother/mother substitutes when I was growing up." Because of the small number of respondents who disagreed or strongly disagreed with those statements, we made the decision to create two broad categories: one that contains those who agreed and strongly agreed, and a second one for those who either disagreed, strongly disagreed, or had no opinion on the matter.

7. Work status encompasses employment and self-employment. The cutoff for part-time/fulltime work is set at 30 hours/week. Job spells had to last a minimum of 6 months in order to be considered. In the case of job interruptions, a minimum duration of 3 months away from work had to be reported. Dated information was collected on a maximum of 5 job spells and 5 work interruption spells.

8. Since retrospective information on income is not available on the GSS data file, we have to rely on proxies in order to assess economic well-being. 
mon-law unions should occupy an intermediate position between those two statuses, since they can be envisioned as less binding, less compelling, and easier to reverse than marriage, especially in the early stages of adulthood.

In accordance with Beaupré et al. (2006), we expect young men who hold at least one post-secondary degree to display a lower probability of coming back home. On the other hand, it is unclear whether school enrolment should act as an incentive to return home or, conversely, as a preventive factor. Prior research on the topic indicates that full-time students tend to postpone home-leaving (Lapierre-Adamcyk et al. 1995; Beaupré and Le Bourdais, 2001). Postponement of home-leaving could possibly imply postponement of home-returning, but it might also signify that the odds of home-returning are lower. Equally noteworthy is the fact that young adults who have left home to pursue postsecondary studies are more likely to come back once they have successfully graduated and are no longer students. It is therefore logical to suppose that school enrolment should reduce the risk of returning home.

Cultural factors such as ethnic origin, mother tongue and province of residence may also prove to affect the timing and incidence of home-returning. For instance, Boyd (2000) and Gee et al. (2003) reported that ethnic groups differ with respect to reasons for leaving and returning home. Consequently, we control for cultural heterogeneity in our sample by using a 5-category variable that stratifies the sample according to the place of birth of the respondent's mother. The effects of mother tongue and province of residence ${ }^{9}$ have also been assessed in previous studies, English-speaking individuals being more at risk of returning home than those who speak French or another language (Mitchell et al. 2000). At the provincial level, residents of Quebec exhibit the smallest propensity to flock back home, whereas people living in the Prairies are more prone to doing so; Ontarians and British Columbians stand in between these two extremes (Billette et al. 2006). We further suggest that there might be a joint impact of both mother tongue and province of residence, as it seems to be the case for home-leaving (Lapierre-Adamcyk et al. 1995; Beaupré et al. 2001). An interaction term between these two variables will thus be incorporated into our final explanatory model.

Home-leaving factors. Finally, the fourth set of factors is related to home-leaving characteristics. Both age at home-leaving and the main reason for leaving home are deemed to influence the risk of returning home (Gee et al. 1995; Aquilino 1996; Mitchell et al. 2000; Gee et al. 2003; Beaupré et al. 2006). Younger ages at home-leaving are associated with a higher probability of return, even though premature home-leaving may also be the consequence of a disturbed family environment (Young 1989; Kerckhoff 1990; Mitchell 1994). As concerns reasons for first home-leaving, school and independence are generally viewed as being positively linked to home-returning, whereas union formation stands in most cases as a preventive factor. ${ }^{10}$

9. Information on the migratory trajectories of the respondents has enabled us to model the province of residence as a time-varying covariate. As a result, there is no need to assume equivalency between province of residence at the time of the survey and province of residence at the time of home-returning.

10. In some instances, multiple reasons for first home-leaving were provided by the respondents. In those cases, we arbitrarily decided to select the main reason according to the following scheme: union $>$ school $>$ work $>$ independence $>$ other. All first three reasons were prioritized over independence because they correspond to a tangible life course transition, whereas independence does not. Union comes first because it is the most binding event and it has long been the primary pathway out of the parental home. School prevails 


\section{Methods}

Data are analysed using a proportional hazards piecewise-constant exponential model with an inverse-Gaussian frailty parameter that enables the modelling of unobserved heterogeneity at the individual level. The basic exponential model is the simplest of parametric survival models, because the baseline hazard is assumed to be constant over time. Let $h\left(t \mid x_{j}\right)$ denote the hazard function and $h_{0}(t)$ denote the baseline hazard, one can see that $h\left(t \mid x_{j}\right)$ is simply equal to the exponentiated version of the right-hand side of the regression equation:

$$
h\left(t \mid x_{j}\right)=h_{0}(t) \exp \left(x_{j} \beta_{x}\right)=\exp \left(\beta_{0}+x_{j} \beta_{x}\right)
$$

Thus, the derivation of the cumulative hazard and survivor functions of the exponential model is rather straightforward:

$$
\begin{aligned}
& H\left(t \mid x_{j}\right)=h\left(t \mid x_{j}\right) t=\exp \left(\beta_{0}+x_{j} \beta_{x}\right) t \\
& S\left(t \mid x_{j}\right)=\exp \left\{-H\left(t \mid x_{j}\right)\right\}=\exp \left\{-\exp \left(\beta_{0}+x_{j} \beta_{x}\right) t\right\}
\end{aligned}
$$

The piecewise exponential model builds on the same parameterization but allows the time axis to be split into different time pieces within which the baseline hazard is still assumed to be constant, but between which variation is expected to occur. Hence, allowance is made for multiple baseline hazards that are conditional on every time piece. Let $\tau_{n}$ be the cut points on the time axis and $I_{t}$ be the time piece, then $I_{t}$ would be defined as:

$$
I_{t}=\left\{t \mid \tau_{n} \leq t<\tau_{n+1}\right\} \quad n=1,2,3, \ldots, N
$$

The survivor and cumulative hazard functions specified above will hold if $t \in I_{t}$. The analytic model used here consists of three different time pieces: one for the first year elapsed after an initial departure, one for the second and third years, and one for the remainder of the hazard function (from $t=3$ to $t=10$ ).

Unobserved heterogeneity, i.e., individual differences due to factors that remain unobserved in the analytic model, is accounted for by the addition of a frailty effect $a_{j}$, assumed to have mean of 1 and variance $\theta$. Hence, the new hazard and survivor functions are now:

$$
\begin{aligned}
& h\left(t \mid x_{j}, \alpha_{j}\right)=\alpha_{j} h_{0}(t) \exp \left(x_{j} \beta_{x}\right) \\
& S\left(t \mid x_{j}, \alpha_{j}\right)=\exp \left\{-\exp \left(\beta_{0}+x_{j} \beta_{x}\right) t\right\}_{j}^{\alpha}
\end{aligned}
$$

The variance $\theta$ is estimated directly from the data and can be referred to as the unobserved variance component of the full model. Conversely, the frailty effect distribution does not merely stem from the data and must be assumed. Even if the pioneering studies on frailty models have relied on the Gamma distribution for its relative convenience (Lancaster 1979; Vaupel et al. 1979), we here assume that the frailty effect follows an inverse-Gaussian distribution. Hougaard $(1984,1991)$ has demonstrated that the family of inverse-Gaussian distributions could also be used as a basis for modelling frailty effects. In proportional hazard parameterization, relative risks (exponentiated coefficients) represent hazard ratios at time $t=0$. The effects that can be attributed to covariate differences become less clear as time passes and the frailty effect takes the lead. In Gamma frailty

over work, for individuals who combine school attendance and full/part-time work are more likely to be referred to as students rather than as workers. 
Table 2. Period-specific and overall effects of the selected independent variables on the risk of returning home within 10 years of first departure (hazard ratios).

\begin{tabular}{ccccccc}
\multicolumn{4}{c}{ Men } & \multicolumn{4}{c}{ Women } \\
\hline \multirow{2}{*}{ year 1 } & years & years & \multirow{2}{*}{ overall } & \multirow{2}{*}{ year 1 } & years & years \\
& $2-3$ & $4-9$ & $2-3$ & $4-9$ & overall
\end{tabular}

Birth cohort

$\begin{array}{rrrrrrrrr}1942-46 & 0.43 \sim & 0.23^{* * *} & 0.67 & 0.38^{* *} & 0.32^{*} & 0.60 & 1.13 & 0.54^{*} \\ 1947-51 & 0.95 & 0.40^{*} & 0.31^{*} & 0.51^{* *} & 0.51 & 0.83 & 0.96 & 0.69 \\ 1952-56 & 0.97 & 0.54^{*} & 0.52 & 0.63^{*} & 0.72 & 0.98 & 0.48 & 0.73 \\ 1957-61 \text { (ref.) } & 1 & 1 & 1 & 1 & 1 & 1 & 1 & 1 \\ 1962-66 & 0.81 & 0.59 \sim & 1.12 & 0.76 & 0.73 & 1.49 & 1.13 & 1.09 \\ 1967-71 & 0.99 & 0.70 & 1.18 & 0.89 & 1.42 & 1.43 & 1.15 & 1.36 \\ 1972-76 & 1.40 & 0.95 & 4.00^{* * *} & 1.50^{*} & 1.98^{*} & 1.96 \sim & 2.25 & 2.05^{* *}\end{array}$

Family structure prior to age 15

Biparental intact family (ref.)

Adoptive family

Stable lone-parent family

1

Stable step-family

0.61

$1 \quad 1$

$0.37^{*}$

0.15

0.66

1

1

1

1

1.14

0.53

$0.17^{* *}$

0.39

$0.33 \sim$

3.25

0.92

1.30

Step-family + lone-parent family

1.18

0.81

0.01

0.5

$0.48 \sim$

1.17

1.01

0.87

Other

$1.35 \quad 0.30 \sim$

0.42

0.54

1.43

0.72

Presence of half/step-siblings

1.03

0.71

1.18

0.64

$0.09 *$

0.63

Yes

No (ref.)

$1.05 \quad 1.13$

0.71

$0.620 .09^{* *}$

$0.21^{*} \quad 0.25^{\star * *}$

$\begin{array}{rllllllll}\text { Yes } & 1.05 & 1.13 & 2.40^{*} & 1.41 \sim & 1.11 & 0.79 & 1.20 & 1.03 \\ \text { No (ref.) } & 1 & 1 & 1 & 1 & 1 & 1 & 1 & 1 \\ \text { Total number of siblings } & 1.05 & 0.93 \sim & 0.90^{*} & 0.96 & 1.01 & 0.96 & 0.90 \sim & 0.96\end{array}$

Highest level of education of most educated parent

Less than secondary (ref.)

High school

$\begin{array}{lll}1 & 1 & 1\end{array}$

$1.13 \quad 1.18$

1

1.00

1.03

1

1

Postsecondary

$1.19 \quad 0.92$

1.35

$1.08 \quad 0.96$

1.31

$0.46^{*}$

0.95

University

$1.23 \quad 0.60 \sim$

0.95

$0.86 \quad 0.59 \sim$

$0.72 \quad 0.63$

0.77

Mother worked prior to age 15

\begin{tabular}{rllllllll} 
Yes & 1.05 & $1.44 \sim$ & 1.22 & $1.26 \sim$ & 0.89 & $1.65^{* *}$ & $1.53 \sim$ & $1.31^{*}$ \\
No (ref.) & 1 & 1 & 1 & 1 & 1 & 1 & 1 & 1 \\
\hline
\end{tabular}

Religious attendance at age 15

Not at all (ref.)

At least once a year

1

$1.73^{*} \quad 1.31$

1

1

1

1

1

11

At least once a month

0.96

1.17

$1.30 \quad 1.41 \sim$

0.73

1.13

Size of the city where respondent lived at age 15

\begin{tabular}{|c|c|c|c|c|c|c|c|c|}
\hline Less than 5,000 & 0.75 & 1.35 & 0.71 & 0.94 & 0.85 & $0.60 \sim$ & $0.27^{\star * *}$ & $0.51^{* * *}$ \\
\hline 5,000 to 24,999 & 0.62 & 1.28 & 0.62 & 0.81 & 0.91 & 0.63 & $0.51 \sim$ & $0.64^{*}$ \\
\hline, 000 to 99,999 (ref.) & 1 & 1 & 1 & 1 & 1 & 1 & 1 & 1 \\
\hline 100,000 to 99 & 0.87 & $1.91^{*}$ & 1. & 1.26 & 1.2 & 1.34 & 0.59 & 1.04 \\
\hline $1,000,000$ or more & 0.82 & $2.52^{* *}$ & 1.15 & 1.44 & 1.22 & 0.88 & 0.52 & 0.83 \\
\hline
\end{tabular}

Emotional closeness to mother when a child

\begin{tabular}{rrrrrrrrr} 
Close (ref.) & 1 & 1 & 1 & 1 & 1 & 1 & 1 & 1 \\
Not close & $2.38^{* * *}$ & 1.14 & 1.67 & $1.64^{*}$ & 0.84 & 1.13 & 0.78 & 0.90 \\
\hline $\begin{array}{r}\text { Emotional closeness to father when a child } \\
\text { Close (ref.) }\end{array}$ & 1 & 1 & 1 & 1 & 1 & 1 & 1 & 1 \\
Not close & 0.70 & $0.57^{* *}$ & $0.54^{*}$ & $0.61^{* * *}$ & 1.11 & 0.79 & 1.28 & 1.02 \\
\hline Had a happy childhood & & & & & & & & \\
Yes (ref.) & 1 & 1 & 1 & 1 & 1 & 1 & 1 & 1 \\
No & 0.71 & 1.75 & 1.34 & 1.23 & 0.90 & 1.01 & 1.69 & 1.12 \\
& & 30 & & & & & &
\end{tabular}


(Table 2, cont'd.)

Work status ${ }^{a}$

\begin{tabular}{|c|c|c|c|c|c|c|c|c|}
\hline Does not work (ref) & 1 & 1 & 1 & 1 & 1 & 1 & 1 & 1 \\
\hline Works part-time & 1.59 & $2.25 \sim$ & 0.84 & 1.64 & 1.40 & 1.42 & 0.63 & 1.13 \\
\hline Works full-time & $0.59^{*}$ & $0.53^{* *}$ & $0.21^{\star * *}$ & $0.44^{* * *}$ & $0.34^{* * *}$ & 0.93 & 0.82 & $0.70^{*}$ \\
\hline \multicolumn{9}{|l|}{ Marital status ${ }^{a}$} \\
\hline No union (ref.) & 1 & 1 & 1 & 1 & 1 & 1 & 1 & 1 \\
\hline Common-law union & 1.28 & 1.14 & 0.46 & 0.83 & 0.75 & $0.41^{*}$ & $0.26^{\star *}$ & $0.40^{* *}$ \\
\hline Marriage & $0.21^{*}$ & $0.01^{* * *}$ & $0.02^{\star \star *}$ & $0.02^{* * *}$ & $0.06^{* * *}$ & $0.03^{* * *}$ & $0.02^{* * *}$ & $0.03^{* * *}$ \\
\hline \multicolumn{9}{|l|}{ Level of education $^{a}$} \\
\hline Less than secondary (ref.) & 1 & 1 & 1 & 1 & 1 & 1 & 1 & 1 \\
\hline High school & 0.79 & $0.21^{* \star *}$ & 0.70 & $0.40^{* * *}$ & 0.72 & $0.34^{* * *}$ & 1.02 & $0.54^{* *}$ \\
\hline Postsecondary & $0.38 \sim$ & $0.22^{\star \star \star}$ & 0.55 & $0.34^{* * *}$ & 0.62 & $0.44^{*}$ & 0.61 & $0.50^{*}$ \\
\hline University & 0.45 & $0.10^{\star * *}$ & 0.61 & $0.34^{* * *}$ & 0.57 & $0.29^{* *}$ & 2.04 & 0.82 \\
\hline \multicolumn{9}{|l|}{ School completion ${ }^{a}$} \\
\hline Yes & 1.00 & $2.48^{\star * *}$ & $1.82^{*}$ & $1.74^{* *}$ & 1.23 & $1.57 \sim$ & 1.25 & 1.44 \\
\hline No (ref.) & 1 & 1 & 1 & 1 & 1 & 1 & 1 & 1 \\
\hline \multicolumn{9}{|l|}{ Region of birth of mother } \\
\hline Canada (ref) & 1 & 1 & 1 & 1 & 1 & 1 & 1 & 1 \\
\hline Rest of the American continent & $0.05^{*}$ & $0.27 \sim$ & $0.17^{*}$ & $0.17^{\star \star \star}$ & 0.66 & 0.49 & $0.03^{* *}$ & $0.36^{*}$ \\
\hline Europe & 1.31 & 0.95 & 1.13 & 1.10 & 0.87 & 0.83 & 0.74 & 0.81 \\
\hline Asia & $0.19 \sim$ & $0.11^{* *}$ & 1.37 & $0.32^{*}$ & $0.17 \sim$ & $0.13^{* *}$ & $0.16^{*}$ & $0.15^{* * *}$ \\
\hline Africa/Oceania & 0.18 & $0.05^{*}$ & --- & $0.04^{* * *}$ & 0.21 & --- & 0.37 & $0.10^{* *}$ \\
\hline \multicolumn{9}{|l|}{ Province $X$ mother tongue } \\
\hline Quebec X English & 0.25 & 0.39 & 0.28 & $0.32^{*}$ & 1.54 & $0.09^{*}$ & $0.22 \sim$ & 0.48 \\
\hline Quebec X French & $0.32^{* * *}$ & $0.44^{* *}$ & 0.62 & $0.40^{\star * *}$ & $0.51^{*}$ & $0.29^{* * *}$ & $0.34^{\star * *}$ & $0.36^{* * *}$ \\
\hline Quebec X Other & 0.52 & $0.01^{* * *}$ & 0.15 & $0.13^{*}$ & --- & --- & -- & --- \\
\hline ROC X English (ref.) & 1 & 1 & 1 & 1 & 1 & 1 & 1 & 1 \\
\hline ROC X French & 0.76 & 0.51 & 1.18 & 0.79 & 1.29 & 0.57 & 0.53 & 0.80 \\
\hline ROC X Other & $0.20^{* *}$ & $0.24^{*}$ & $0.13^{* *}$ & $0.20^{* * *}$ & $0.31^{*}$ & 0.65 & 0.63 & $0.53^{*}$ \\
\hline
\end{tabular}

Age when first left home

$\begin{array}{rllllllll}\text { Less than } 20 & 1.37 & 1.72^{*} & 0.73 & 1.35 \sim & 1.79^{*} & 2.13^{* * *} & 4.33^{* * *} & 2.62^{* * *} \\ 20-24 \text { (ref.) } & 1 & 1 & 1 & 1 & 1 & 1 & 1 & 1 \\ 25 \text { and over } & 0.51 & 0.48 & 0.23^{* *} & 0.39^{* *} & 1.71 & 1.38 & 1.57 & 1.40\end{array}$

Reason first left home

\section{Constant terms}

$\begin{array}{rcccccccc}\text { Union } & 0.30^{* *} & 0.24^{* *} & 1.39 & 0.50^{*} & 0.31^{* * *} & 0.33^{* * *} & 1.19 & 0.51^{* *} \\ \text { School } & 1.08 & 1.10 & 2.10^{*} & 1.28 & 1.07 & 1.03 & 1.60 & 1.28 \\ \text { Work } & 1.14 & 0.82 & 0.55 & 0.81 & 0.70 & 0.47^{* *} & 0.87 & 0.63 \sim \\ \text { Independence (ref.) } & 1 & 1 & 1 & 1 & 1 & 1 & 1 & 1 \\ \text { Other } & 1.98 & 0.79 & 0.47 & 1.03 & 1.85 \sim & 0.80 & 0.86 & 1.24\end{array}$

$\begin{array}{rrrrr}\text { First time piece } & -1.85^{* *} & -1.38^{* * *} & -1.34^{*} & -1.49^{* * *} \\ \text { Second time piece } & 0.94 & 0.59 & 0.27 & 0.34 \\ \text { Third time piece } & -0.26 & -0.45 & -1.70^{*} & -0.88 \\ \text { Theta } & 30.00^{* * *} & 28.65^{* * *} & 18.39^{* * *} & 23.98^{* * *} \\ \text { chibar2 theta=0 } & 191.34^{* *} & 193.31^{* * *} & 161.33^{* * *} & 156.78^{* * *} \\ \text { Log likelihood } & -3279.67 & -3378.44 & -3617.64 & -3714.26 \\ \mathrm{~N} & 4,803 & 4,803 & 5,672 & 5,672\end{array}$

a These variables are time-varying covariates whose values are subject to change over time $\sim p<0.1^{*} p<0.05^{* *} p<0.01{ }^{* * *} p<0.001$; Sampling and bootstrap weights have been applied Source: General Social Survey, Cycle 15. 
models, the effect of the independent variables vanishes completely and is ultimately outweighed by the frailty effect. Such is not the case, however, with inverse-Gaussian frailty models, whereby a greater homogeneity among the survivors prevents the downfall of the effect of covariate differences that tends instead towards the square root of the hazard ratio at time $t=0$. Stated otherwise, the estimation of our frailty parameter is more conservative than it would be with a Gamma probability density function.

Period-specific and overall hazard ratios representing the effect of the independent variables on the probability of experiencing a first return home are shown in Table 2. Hazard ratios are to be interpreted in relation to the reference category, which is set equal to 1 . Hence, a hazard ratio of 2 , significant at the 0.05 level, ${ }^{11}$ for one of the categories of an independent variable would imply that individuals with this characteristic are twice as likely as members of the reference category to experience a first return home within the time piece that is being considered. Conversely, a hazard ratio of 0.5 , significant at the 0.05 level, would imply that displaying such a characteristic halves the risk to return home when compared with members of the omitted category.

In all the models presented below, robust variance estimates were obtained using the two hundred sets of mean bootstrap weights supplied by Statistics Canada, along with the GSS master file. These weights were computed in order to adjust for the impact of the multistage survey design on the standard errors of descriptive statistics and model estimates. For the purpose of the survey, the Canadian territory was primarily divided into strata that were further split into clusters. Since the former tend to artificially decrease standard errors, and the latter rather tend to inflate them, it is sensible to assume that a more robust estimate of the real sampling variance can be obtained by taking the structure of the sampling design into consideration (Rust and Rao 1996; Shao 1996). For more details on the application of mean bootstrap weights to complex survey data, see Buckley and Chowhan (2005).

\section{Results}

\section{Overall effects}

Table 2 separately displays hazard ratios for every time piece, as well as for the overall model estimated over the whole time range of the hazard function. As expected, some cohort effects seem to be at play for both genders, even though the results do not reflect a constant progression from one given five-year cohort to the next. In fact, only late Gen-Xers appear to face a significantly higher risk of experiencing a first return home than members of the 1957-61 cohort. This finding holds for both sexes, although sex differences are observed in the timing of returns, which tend to occur earlier after an initial departure among women than among men. Men born prior to 1957 were also less likely to come back home, whereas only pre-boomers appear to significantly differ from members of the reference cohort among women.

Childhood family background also seems to affect the likelihood of home-returning. It was hypothesized that alternative types of family structure should curb young people's propensity to return home. This appears to be true for lone-parent families (men) and

11. We chose to also report results significant at the 0.1 level, for many categories of some independent variables account for but a very small fraction of the sample (common-law unions, nonstandard types of family structure, part-time workers...) and would have probably reached higher significance had a larger number of cases been considered. 
other forms of family structure (women). Yet no significant effect is observed for stepfamilies. Moreover, the presence of half/step-siblings in the household appears to have a positive impact on the risk of returning home. It is also worthy of mention that, in spite of their apparent lack of significance, adoptive families do influence home-returning among women (at the 0.1 level). Since their effect is negative for early returns and positive for intermediate ones, failing to make allowance for period-specific estimates leads to a situation in which these opposite effects cancel each other out.

Socio-economic well-being during childhood, proxied by indicators such as parental education and maternal employment, also yields some mixed results. The former was expected to increase the risk of coming back home. It seems to either have no effect at all in most instances or to even decrease this risk in the case of women who had at least one university-educated parent. However, results for maternal employment are consistent with our predictions and appear to significantly increase this risk for both genders.

Some other variables relating to the respondents' childhood also surface as significant predictors of home-returning. Oddly enough, men raised in moderately religious family environments have a higher probability to refill the nest than those who did not attend religious services at age 15. City size also matters in the case of women, among whom those who lived in a rural area or a small city (less than 25,000 inhabitants) incur a reduced risk to become returners. As for recollections of childhood happiness and emotional closeness to both parents, our results suggest that they have no impact on women's homeward trajectories but that men close to their mother would be 64 per cent more likely to experience a first (early) return to the parental home, whereas the net effect of a close father-son relationship would result in a 39 per cent reduced likelihood.

Shifting to the effect of socio-economic and demographic factors, it appears that working full-time, as opposed to not working at all, diminishes the probability of homereturning for both genders. Married people almost have a null risk to come back home when compared to single individuals. On the other hand, common-law unions only act as a protective factor in the case of women, for whom it decreases by 60 per cent the eventuality of a return to the parental home.

While school completion makes both men and women more likely to come back home (although the hazard ratio for male respondents reaches a higher level of significance), all levels of education seem to negatively affect the risk of a return. However, women who hold a university degree do not significantly differ from those who did not graduate from high school in terms of propensity.

Ethnocultural factors also appear to be momentous when it comes to explaining individual differences in home-returning behaviours. Basically, this whole nest-refilling phenomenon seems to be a characteristic of people whose mothers were born either in Canada or in Europe. Both men and women who can claim another cultural heritage also have a significantly lower risk of experiencing the reverse transition under study. This finding is further supported by the observed hazard ratios for the interaction term between province and mother tongue. Individuals whose mother tongue is neither English nor French display a much lower propensity to return home than their English-speaking counterparts who live outside Quebec. It is noteworthy that it was impossible to estimate a hazard ratio for female speakers of a third language living in Quebec, because none of them had actually experienced a return home by the time they were interviewed. Results also show that whereas French-speaking Canadians who do not live in Quebec do not significantly differ from members of the reference category, those who live in Quebec do. 
This finding also applies to English-speaking Quebecers (although the overall estimate for women is not significant), thus suggesting that a provincial effect is at work in the determination of home-returning.

Finally, age at home-leaving influences the risk of returning home. Both men and women who leave before their twentieth birthday are more likely to return, although the effect seems to be much stronger among women. A late departure from the parental home (at or past age 25) also seems to significantly reduce the probability of homereturning among men but not among women. As for the routes out of the family nest, men and women who leave home to enter a union incur a half-reduced risk of returning when compared to those who leave to achieve independence. Work as a destination also seems to decrease the probability of a return home in the case of women.

\section{Period-specific effects}

Since we are here examining transition reversals that took place over a 10 -year period, the overall effects of the coefficients might conceal some heterogeneous behaviours in terms of timing. We here profile, for both genders, typical early, intermediate, and late returners with respect to results shown in Table 2.

Early Male Returner (within the first year): He is moderately religious, not close to his mother, not born in 1942-46, not raised in a lone-parent family, not married (nor did he leave to enter a union). He does not hold a post-secondary degree; his mother was not born in Asia or in America (Canada excepted). He is not a French-speaking Quebecer or a speaker of a third language living outside Quebec.

Early Female Returner (within the first year): She was born between 1972 and 1976 and was not raised in an adoptive or lone-parent family. Her parents do not have a university degree. She does not work full-time, is not married and does not have an Asiatic heritage. She is neither a French Quebecer, nor a native speaker of a third language. She left home before she turned 20 for a reason that has nothing to do with school, work, conjugality, or independence.

Intermediate Male Returner (within the 2nd or 3rd year): He was born after 1967 and was not raised in an alternative type of family. He has few siblings, works parttime, is out of school, has less than a high school degree, and was close to his father when a child. He was raised in a city of more than 100,000, his parents are not university-educated but his mother worked throughout his childhood. He left home before he turned 20, is single, is either of Canadian or European heritage; he is either a native Englishspeaker or a Francophone living outside Quebec.

Intermediate Female Returner (within the 2nd or 3rd year): She was born in 1972-76, was adopted, had a working mother, and does not come from a rural area. She is single, out of school, and has less than a high school degree. She does not have an Asian heritage, does not live in Quebec, and left home while she was under 20 for a reason other than work or union formation.

Late Male Returner (3 years or more after departure): He was born after 1971 and was not raised in a lone-parent family. He does not have many siblings but some of them are either half- or step-siblings. He has a religious background, was close to his father when a child, does not work full-time, and is not married. His mother was not born in an American country (Canada excluded) and he is not a speaker of a third language living outside Quebec. He left home to attend school before he turned 25 but is no longer a student. 


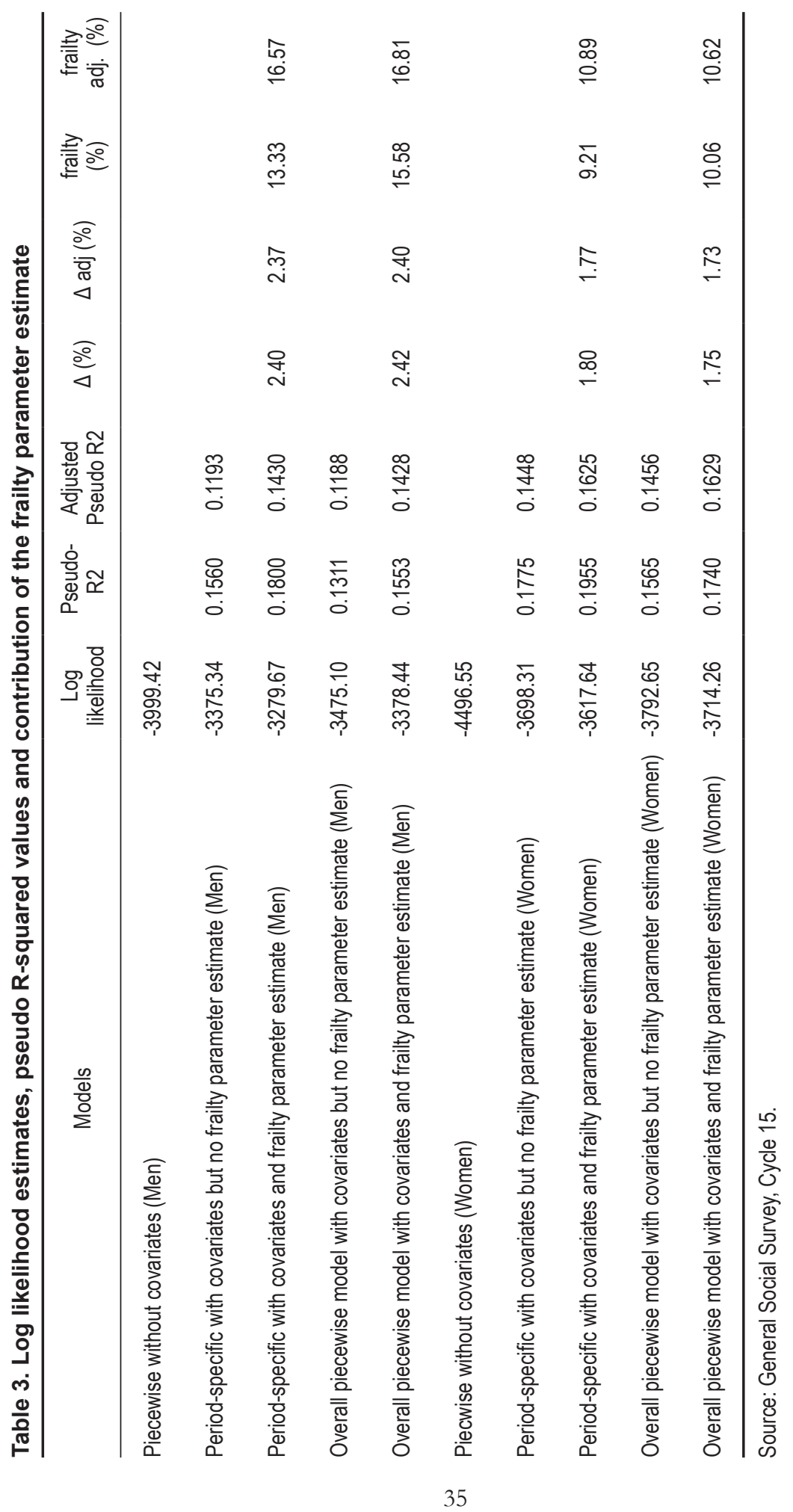


Late Female Returner (3 years or more after departure): She was raised in a stable family (no alternation of lone and stepfamily episodes; no "other" type of family) and has few siblings. Her parents have either more or less than a high school degree and her mother used to work when she was a child. She comes from a city of at least 25,000 inhabitants, is single and left home before age 20. She does not live in Quebec and her heritage is either Canadian or European.

\section{Effect of unobserved individual differences}

Values appearing on the "Theta" row in Table 2 correspond to the estimated variance of the frailty effect $a_{j}$ for each of the models. This variance component is presented along with its standard error, as well as a likelihood-ratio test of its significance. ${ }^{12}$ In all models, the variance component attributed to unobserved characteristics appears to be highly significant. Moreover, taking into consideration period-specific estimates does not seem to lessen the impact of unobserved heterogeneity. Our hypothesis that homereturning patterns are in part the outcome of individual-level characteristics that remain unaccounted for in our explanatory model thus seems to be empirically verified.

An attempt at assessing the relative contribution of the inverse-Gaussian frailty parameter introduced into both the period-specific and the overall piecewise models is presented in Table 3. Unlike linear regression models that are estimated using ordinary least squares, survival models are estimated by means of maximum likelihood and do not come along with a measure of the variability in the dependent variable that is explained by the model, such as an $\mathrm{R}^{2}$. A certain number of methods have been proposed to compute pseudo- $\mathrm{R}^{2}$ for models estimated by maximum likelihood, and we have chosen to use McFadden's method in order to obtain an approximation of the explanatory power of our statistical model, as well as of the contribution of the variance component attributed to the frailty parameter. McFadden's pseudo- $\mathrm{R}^{2}$ is computed as follows:

$$
\text { Pseudo } \mathrm{R}^{2}=1-\frac{\ln \log \text { likelihood (full model) }}{\ln \log \text { likelihood (model without covariates) }}
$$

As in the case of linear regression, an adjusted version of this $\mathrm{R}^{2}$ can be computed so as to penalize models that include too many insignificant predictors. This is done by subtracting the number of predictors included in the model from the numerator:

$$
\text { Pseudo } \mathrm{R}^{2}=1-\frac{\ln \log \text { likelihood (full model) - \# of predictors }}{\ln \log \text { likelihood (model without covariates) }}
$$

In our case, the inclusion of a frailty parameter estimate induces an increase of about 0.024 in the adjusted pseudo- $\mathrm{R}^{2}$ value of both the overall and the period-specific models for males, while the gain is smaller for females $(0.0177$ for the period-specific model and

12. Using a likelihood-ratio test to verify whether a variance component significantly differs from zero happens to be problematic since variances are always greater than zero. Rather than relying on a likelihood-ratio test statistic following a chi-square distribution with one degree of freedom (i.e., what would be the case if we were to test the significance of a regular independent variable), we here use a 50:50 mixture of a chi-square with zero degree of freedom and a chi-square with one degree of freedom (what is called a chibar square, 'bar' standing for mean). As a result, the computed p-value of the likelihood-ratio test statistic is equal to half the probability that the value of this statistic happens to be smaller than the limit value of a chi-square with one degree of freedom (for more details, see Gutierrez et al. 2001). 
0.0173 for the overall model). This represents slightly more than 16 per cent of the total explanatory power of both models for men, and close to 11 per cent for women. Such a finding involves that a fair but not overwhelming part of the variance in the hazard of home-returning is accounted for by unobserved individual characteristics, and that their relative impact seems to be greater among men than among women.

\section{Discussion}

Overall, our findings suggest that all four types of determinants considered in this study influence the risk of returning home, and so do other unmeasured factors, hence bringing support to our initial claim that heterogeneity, both systematic and non-systematic, is the crux of home-returning. On the generational time axis, our results suggest that the upsurge in the number of boomerang kids is a recent phenomenon that mainly concerns the youngest cohort considered for the purpose of this study (late Gen-Xers). It can easily be hypothesized that this finding is likely to extend to members of more recent generations whose behaviours could not be examined here. Moreover, this generational trend also appears to have a significant gendered dimension: among late Gen-Xers, men tend to be late returners while women would be more likely to return home within the first three years following their first departure.

Life course theory also emphasizes the importance of childhood and family background factors in the determination of later life-course outcomes. We have here controlled for a broad set of retrospective features including family structure, presence of siblings, parental education, maternal work status, religious attendance, city size, emotional closeness to both parents, and childhood happiness. While we fail to replicate the findings of many previous studies, according to which young people raised in stepfamilies are consistently less likely to experience a return home after a first launch (Gee et al. 1995; Goldscheider and Goldscheider 1998; Mitchell et al. 2004; Beaupré et al. 2006), most of the findings regarding other background factors are in line with our expectations but are qualified by the estimation of a period-specific model that makes allowance for timing heterogeneity. For instance, results regarding the number of siblings show that there is indeed a "crowded nest" effect, but it is limited to late returns. Also, parental households settled in larger cities elicit more returns among males, but these returns tend to occur within 2-3 years of a first departure. Generally speaking, it is possible to identify trends in the timing of the reverse transition. Early returns seem in most cases to be conditioned by early departures, which are, up to a certain point, associated with family dissension (Young 1989; Kerckhoff 1990; White 1994); intermediate returns are observed among individuals who left prior to age 20 and whose parents are well-off and live in a metropolitan area; as for late returns, they are related to religiosity, school completion, and cohort membership among males, but have roughly the same characteristics as intermediate returns among females.

Similar conclusions can be drawn with regard to the other two types of determinants included in our explanatory model. Full-time work and marriage are very strongly negatively associated with the probability of experiencing a return, although the former association is stronger among males than among females. As for part-time work, our results suggest that it constitutes an adequate proxy for economic precariousness, insofar as it never significantly differs from not working. At the 0.1 level, it even doubles the risk of being an intermediate returner among males. 
On another level, cultural and provincial factors also significantly affect the likelihood of home-returning. It has long been acknowledged that ethnic background factors are instrumental in the determination of residential independence (Goldscheider and Goldscheider 1999; Boyd 2000; Gee et al. 2003). It is even more conspicuous with regard to its reversal: home-returning seldom occurs among individuals with a non-Canadian/ European background. This can either be interpreted as a consequence of the irreversibility of home-leaving in many cultures, most probably because of its still strong interconnection with marriage, or as a token of the popularity of multigenerational living arrangements in many cultures in which neolocality is not systematic, hence making both home-leaving and home-returning rarer.

While it was at first unclear whether the French/English dichotomy evidenced by Mitchell et al. (2000) was due to linguistic or provincial factors, our results show that living in Quebec reduces the risk of being a boomerang kid among both French- and Englishspeaking individuals, whereas Francophones living outside Quebec do not significantly differ from their English-speaking counterparts. Many reasons can be put forward so as to explain why living in Quebec makes both men and women less likely to return home; among them, we can propose the following: (1) both men and women tend to leave home at later ages in Quebec (Billette et al. 2006); (2) shelter costs are lower in Quebec than anywhere else in Canada (Verenka and Little 2007); (3) tuition fees are lower than anywhere else in Canada (Statistics Canada 2006); and (4) because of the popularity of nonmarital cohabitation, union, as a pathway out of the family environment, is more frequent than in other provinces, hence leading to a statistically larger number of relatively more stable living arrangements (Billette et al. 2006).

In addition, unobserved predictors seem to be prominent, but what lurks inside the Pandora's box labelled as unobserved heterogeneity? The first predictor that comes to mind is income. Although retrospective information on income, if it did exist, would be too inaccurate to be considered in a survival-type analysis of home-returning, unquestionably the inclusion of such a factor in the explanatory model would have impacted the estimated results. Yet we are confident that unobserved heterogeneity is to be attributed to other factors, as well.

There has been scant research on the body of motives underlying the decision to return home. Using a Canadian sample, Mitchell (2004) has found that, however diverse those motives may be, about 85 per cent of them fall into the broad category of economic reasons. For instance, some young adults do return home to muster enough money to be able to supply a down payment on a house, while some others just need a home base while they transit from school to another life-course stage of their existence. Quite interesting is the fact that many agree they could afford to live on their own but prefer to avoid doing so because it would make them worse off from a financial standpoint. Therefore, economic reasons do not necessarily reflect economic hardship. They may well correspond to individual strategies that aim at ensuring a forecasted goal achievement. In this respect, returners resemble late home-leavers who envision intergenerational co-residency as a means to prepare a suitable future.

Furthermore, Mitchell (2004) also found that the remaining 15 per cent of respondents who had not returned home for economic reasons had done so either because they had to take care of their sick/aging parents, had undergone a separation/divorce/widowhood, or had psychological or health-related reasons to do so. Each of those reasons may be viewed as pathways to explore in future research on the topic. 
In closing, some statements must be made about the limitations of the present research. First of all, it would have been interesting to rely on a more comprehensive set of independent variables to estimate unobserved heterogeneity with greater accuracy. Information on income, of course, would have been of great relevance, and so would have a better measurement of family relations and intergenerational conflict. Since homereturning affects parents as well as children (Clemens and Axelson 1985; Aquilino 1996; Mitchell and Gee 1996; Veevers and Mitchell 1998; Mazzuco 2006), a more detailed account of respective feelings on both sides would have been of a great help. Indicators of financial dependency and generational transfers of money and other resources would have proved useful, as well. Also, contextual information pertaining to the housing market (prices and availability), tuition fees, and provincial policies regarding student loan repayment might have been interesting controls to incorporate into a full model of homereturning.

Finally, considering multiple-return episodes would have ultimately led to a more thorough understanding of the phenomenon, inasmuch as a proportion of this unobserved heterogeneity might be accounted for by the fact that multiple home-returners are likely to differ, from a life-course perspective, from single-time home-returners. Lifetime residential trajectories would be required to better capture the very essence of this phenomenon, especially for the sake of generations born in the 1980s and 1990s, among which home-returning is on the verge of becoming an almost "standard" life-course transition.

\section{Acknowledgements}

This paper is part of the first author's doctoral research that was funded by the Social Sciences and Humanities Research Council. Statistics Canada's confidential data were accessed through the Research Data Centre Program at the Quebec Interuniversity Centre for Social Statistics (QICSS) and the Carleton, Ottawa, and Outaouais Local Research Data Centre (COOL RDC). However, while the research and analysis are based on data from Statistics Canada, the opinions expressed do not represent the views of Statistics Canada.

\section{References}

Aquilino, W.S. 1996. The returning child and parental experience at midlife, in The Parental Experience in Midlife, edited by C.D. Ryff and M.M. Seltzer. Chicago: University of Chicago Press.

Aquilino, W.S. 1990. The likelihood of parent-child coresidence: Effects of family structure and parental characteristics. Journal of Marriage and the Family 52:405-19.

Beaupré, P. and C. Le Bourdais. 2001. Le départ des enfants du foyer parental au Canada. Cahiers Québécois de Démographie 30:29-62.

Beaupré, P., P. Turcotte, and A. Milan. 2006. Junior comes back home: Trends and predictors of returning to the parental home. Canadian Social Trends 82:28-34.

Billette, J.-M., C. Le Bourdais, and B. Laplante. 2006. Le contexte de l'indépendance résidentielle au Canada. Cabiers Québécois de Démographie 35:83-122.

Bozon, M. and C. Villeneuve-Gokalp. 1994. Les enjeux des relations entre générations à la fin de l'adolescence. Population 6:1527-56. 
Clemens, A.W. and L.J. Axelson. 1985. The not-so-empty nest: The return of the fledgling adult. Family Relations 34:259-64.

Corijn, M. and E. Klijzing (eds.) 2001. Transitions to Adulthood in Europe. Dordrecht: Kluwer Academic Publishers.

Elder, G.H., Jr. 1985. Life Course Dynamics. Ithaca, NY: Cornell University Press. . 1995. The life course paradigm: Social change and individual development, in Examining Lives in Context: Perspectives on the Ecology of Human Development, edited by P. Moen, G.H. Elder, Jr., and K. Luscher. Washington, DC: American Psychological Association.

- 2003. The life course in time and place, in Social Dynamics of the Life Course: Transitions, Institutions, and Interrelations, edited by W.R. Heinz and V.W. Marshall. New York: Aldine de Gruyter.

Ermisch, J. and M. Francesconi. 2001. Family matters: Impacts of family background on educational attainment. Economica 68:137-56.

Gee, E.M., B.A. Mitchell, and A.V. Wister. 1995. Returning to the parental 'nest': Exploring a changing Canadian life course. Canadian Studies in Population 22:121-44.

- 2003. Home leaving trajectories in Canada: Exploring cultural and gendered dimensions. Canadian Studies in Population 30:245-70.

Goldscheider, F.K. and C. Goldscheider. 1993. Leaving Home Before Marriage: Ethnicity, Familism and Generational Relationships. Madison: University of Wisconsin Press.

. 1998. The effect of childhood family structure on leaving and returning home. Journal of Marriage and the Family 60:745-56.

- 1999. The Changing Transition to Adulthood: Leaving and Returning Home. Thousand Oaks, CA: Sage Publications.

Goldscheider, F.K., C. Goldscheider, P. St. Clair, and J. Hodges. 1999. Changes in returning home in the U.S., 1925-1985. Social Forces 78:695-720.

Gutierrez, R.G., S.L. Carter, and D.M. Drukker. 2001. On boundary-value likelihood-ratio tests. Stata Technical Bulletin 60:15-18.

Hagestad, G.O. and B.L. Neugarten. 1985. Age and the life course, in Handbook of Aging and the Social Sciences, edited by R.H. Binstock and E. Shanas. New York: Van Nostrand Reinhold, pp. 35-61.

Hougaard, P. 1984. Life table methods for heterogeneous populations: Distributions describing the heterogeneity. Biometrika 71:75-83.

- 1991. Modelling heterogeneity in survival data. Journal of Applied Probability 28:695-701.

Kerckhoff, A.C. 1990. Getting Started: Transition to Adulthood in Great Britain. Boulder: Westview.

Lancaster, T. 1979. Econometric methods for the duration of unemployment. Econometrica 47:939-56.

Lapierre-Adamcyk, É., C. Le Bourdais, and K. Lehrhaupt. 1995. Le départ du foyer parental des jeunes Canadiens nés entre 1921 et 1960. Population 4/5:1111-35.

Mazzuco, S. 2006. The impact of children leaving home on the parents' wellbeing: A comparative analysis of France and Italy. Genus 62:35-52.

Mitchell, B.A. 1994. Family structure and leaving home: A social resource perspective. Sociological Perspectives 37:651-71.

- 2004. Home, but not alone: Social and economic aspects of young adults living at home. Atlantis: A Journal of Women's Studies 35:423-43.

—. 2006a. The Boomerang Age: Transitions to Adulthood in Families. New Brunswick, NJ: Transaction Publishers.

- 2006b. The boomerang age from childhood to adulthood: Emergent trends and issues for aging families. Canadian Studies in Population 33:155-78.

Mitchell, B.A. and E.M. Gee. 1996. Boomerang kids and midlife parental satisfaction. Family Relations 45:442-8. 
Mitchell, B.A., A.V. Wister, and E.M. Gee. 2000. Culture and coresidence: An exploration of variation in home-returning among Canadian young adults. Canadian Review of Sociology and Anthropology 37:197-222.

- 2002. There's no place like home: An analysis of young adults' mature coresidency in Canada. International Journal of Aging and Human Development 54:1-28.

- 2004. The family and ethnic nexus of home leaving and returning among Canadian young adults. Canadian Journal of Sociology 29:563-95.

Paul, P. 2001. Echo Boomerang. American Demographics 23:44-50.

Price, S.J., P.C. McKenry, and M. Murphy. 2000. Families Across Time: A Life Course Perspective. Los Angeles: Roxbury Publishing Co.

Rust, K. and J.N.K. Rao. 1996. Variance estimation for complex estimators in sample surveys. Statistics in Medical Research 5:381-97.

Shao, J. 1996. Resampling methods in sample surveys (with discussion). Statistics 27:203-54.

Statistics Canada. 2006. University Tuition Fees. The Daily, September $1^{\text {st }}, 2006$. Accessed via http://www.statcan.ca/Daily/English/060901/d060901a.htm (retrieved August 27, 2007).

Tang, S. 1997. Repeated home-leaving behavior of American youth. Journal of Comparative Family Studies 28:147-59.

Vaupel, J.W., K.G. Manton, and E. Stallard. 1979. The impact of heterogeneity in individual frailty on the dynamics of mortality. Demography 16:439-54.

Veevers, J. and B.A. Mitchell. 1998. Intergenerational exchanges and perceptions of support within "boomerang kid" family environments. International Journal of Aging and Human Development 46:91-108.

Verenka, L.-P. and D. Little. 2007. Changes and challenges for residential real estate lessors (Cat. No. 63F0002XIE052). Ottawa: Statistics Canada.

Ward, R., J. Logan, and G. Spitze. 1992. The influence of parent and child needs on coresidence in middle and later life. Journal of Marriage and the Family 54:209-21.

White, L. 1994. Coresidence and leaving home: Young adults and their parents. Annual Review of Sociology. 20:81-102.

Wister, A.V., B.A. Mitchell, and E.M. Gee. 1997. Does money matter? Parental income and living arrangement satisfaction among "boomerang" children during coresidence. Canadian Studies in Population 24:124-45.

Young, C. 1989. The effect of children returning home on the precision of the timing of the leaving-home stage, in Later Phases of the Family Cycle: Demographic Aspects, edited by E. Grebenick, C. Hohn, and R. Mackensen. Oxford: Clarendon Press, pp. 161-84. 